\title{
Experimental research of steel-concrete load bearing components of bridge column piers
}

\author{
Nataliia Smirnova ${ }^{1}$, Sergiy Bugayevskiy ${ }^{2}$, Andrii Ihnatenko ${ }^{2}$, Olena Synkovska ${ }^{2,}$, and Maksym Kovalov ${ }^{3}$ \\ ${ }^{1}$ Kharkov National Automobile and Highway University, Road Building and Maintenance Department, 25 Yaroslava Mudrogo st., \\ 61002 Kharkiv, Ukraine \\ ${ }^{2}$ Kharkov National Automobile and Highway University, Department of Bridges, Constructions and Structural Mechanics, 25 \\ Yaroslava Mudrogo st., 61002 Kharkiv, Ukraine \\ ${ }^{3}$ Ukrainian State University of Railway Transport, Structural Mechanics and Hydraulics Department, 7 Feierbakh Sq., Kharkiv, Ukraine
}

\begin{abstract}
A new constructive design of a bridge column pier, which is a load-bearing component of bridges and overpasses as well as of complex multilevel interchanges underlying a transport infrastructure, is proposed. The design is based on a steel mesh casing that is made from a solid-web plate by means of cutting meshes and further expansion of the solid-web plate using non-waste technology. Experimental research data on the bearing capacity and deformability of the cylindrical steel-concrete load bearing components of bridge column piers are provided. They are compared with research data on load bearing components having a solid casing. To make the experimental picture complete, analogous research data on cylindrical concrete load bearing components are provided. This experiment includes static and low-cycle loadings of samples under axial compression mentioned above. On the basis of the information obtained, the effort and travel fields are formed, the critical forces of structure buckling are determined. The analysis of the rationality of the cylindrical steel-concrete load bearing component of bridge column piers is carried out, using the experimental research data. To verify the research data, which are obtained in the course of the study of the critical forces of cylindrical steel-concrete load bearing component buckling, the experimental results are compared with theoretical ones.
\end{abstract}

\section{Introduction}

An important constituent of transport infrastructure is the engineering constructions such as bridges, overpasses and complex multilevel interchanges. However, taking into consideration their multicomponent structure, each separate component needs close scrutiny. This paper deals with a bridge column pier.

To build bridge piers, in addition to traditional concrete and reinforced concrete units, various steelconcrete load bearing units are used. As a rule, they are tubes that are filled with concrete. An advantage of a tubeconcrete structure is a decrease in concrete consumption 1,5-2 times, as a result, the weight of the structure decreases by 1,8-3 times and working hours halve because there is no rebar placement and no removal of the formwork $[1,2,3]$. However, steel consumption increases (the percentage of the reinforcement of tube-concrete structures is $3-20 \%$, in this case it is $4,88 \%$ ); there is a reduced bond between casing and concrete due to the smooth surface of a steel tube as well as high susceptibility of a steel solid casing to mechanical damage and corrosion as a concrete cover is absent.

A steel-concrete class, in addition to tube-concrete units, also includes various systems having confinement (lateral) reinforcement such as radial rings, hoops, spiral winding etc. $[4,5]$. It should be noted that this reinforcement has both advantages and disadvantages. The advantages are the increase of the bearing capacity, metal and concrete saving. The disadvantages are high labour intensity to manufacture the structures and heavy longitudinal deformation of the structures.

The analysis of the disadvantages of steel-concrete load bearing units having a solid steel casing (tubeconcrete units) and the advantages and disadvantages of load bearing units having lateral reinforcement enables us to offer the solution of the cylindrical steel-concrete load bearing unit of a pier having a mesh case (Fig. 1) [6,7].

This casing is a steel plate of the St3PS grade having a mesh with equally distributed cells (Fig. 2).

This plate is made using non-waste technology by cutting and further expanding the areas of a solid steel plate-workpiece using a special press [8]. In this case the thickness is $4 \mathrm{~mm}$. This treatment enables us to decrease the weight of a mesh in comparison with a solid plate of the same dimensions, saving the required strength parameters (Table 1).

In this research we use the PVL 406mesh; steel saving is $52 \%$; the reinforcement percentage of a mesh casing is $2,33 \%$.

It should be noted that in terms of strength properties a steel-concrete structure having a mesh case is between an analogous reinforced concrete structure and an analogous tube-concrete one, integrating their best qualities.

\footnotetext{
* Corresponding author: iglema@meta,ua
} 
a)

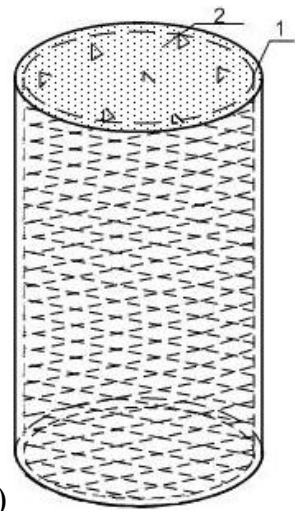

b)

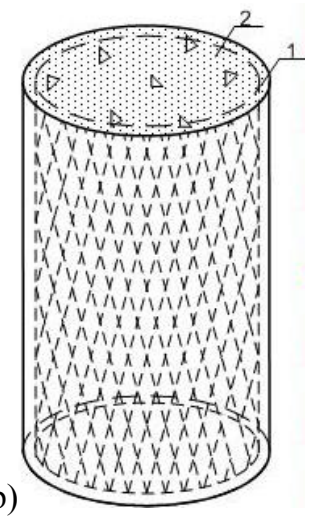

Fig. 1. Steel-concrete load bearing unit having a mesh as casing: a) cells are located across the generatrix; b) cells are located along the generatrix.
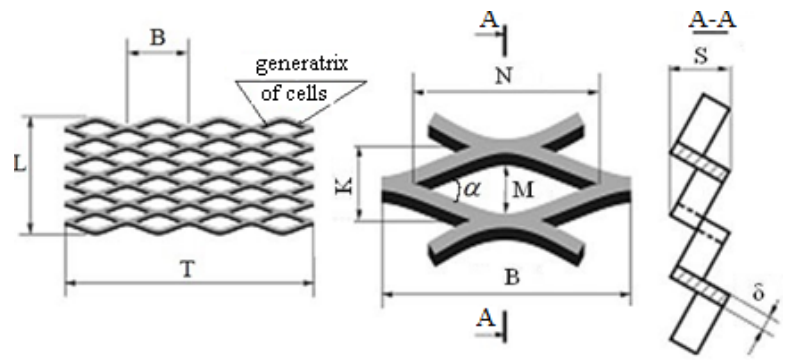

Fig. 2. Main geometric characteristics of an expanded metal mesh.

So, a mesh case carries out the function of dispersed reinforcement in addition to its main function due to volumetric rhombic cells. It differs dramatically from externally similar composite structures that are made by means of layer-by-layer winding of steel cords as a net or spiral. At the same time, an improved bond between the plate and a concrete core, even without special anchors, as well as increased corrosion resistance and fireproof of a structure due to a concrete cover are the features of a structure (Fig. 1). In turn, a variation on both the plate size and the angle of generatrix inclination enables us to set the necessary stiff characteristics to a structure [7,9]. And it has been proven theoretically that a rational approach to optimally compress the concrete core of a mesh casing is a direction of cells across the generatrix of a steel-concrete load bearing unit [9]; it is experimentally proven in this paper.

\section{Methodology of research}

Thus, in order to verify the rationality of the structure of the steel-concrete load bearing unit, experimental research is conducted in Kharkov National University of Construction and Architecture [10]. Taking into account the features of the operation of piers in transport infrastructure, the programme of the testing includes central static (STcS) and low-cycle (MTcS) compression of the samples of four types: steel-concrete samples having a solid casing, steel-concrete samples having a mesh casing when cells are located along and across generatrix, and concrete samples without reinforcement (Fig. 3).

All the casings are cylindrical iron cover that is made from solid or mesh steel sheets. Solid casing is made from steel sheet St3PS2 having a thickness of $4 \mathrm{~mm}$ by analogy with the thickness of the plate-workpiece of a mesh plate [8]. The joints of the casing sheets of solid and mesh casings with cells along generatrix are rolled and buttwelded; the joints of the casing sheets of a mesh casing with cells across generatrix are welded using an overlay narrow plate (Fig. 4a).

Concreting of the samples under research is made in two stages: first, the steel-concrete samples having solid and mesh casings with cells along the generatrix and the concrete samples without reinforcement and second, the steel-concrete samples having a mesh casing with cells across generatrix and the concrete samples without reinforcement. The ends of the steel-concrete samples of all types as well as the concrete samples without reinforcement are aligned with the casing; the horizontal level is under strict control. All the samples are stored in laboratory conditions for 28 days at an air temperature of $(20 \pm 5)^{\circ} \mathrm{C}$. The ends of samples are covered by a layer of wet sand to prevent them from contraction cracks.

The concreting of steel-concrete samples having a mesh casing with cells along and across generatrix as well as concrete samples without reinforcement is made using a disposable formwork for monolithic construction such as AMICOTUBE (Fig. 4b). The concreting of the steelconcrete samples having a solid casing needs no additional formwork.

The main power unit to test the building structures is the P-500hydraulic press. The upper base plate of the press is fixed on a movable traverse beam and it has a selfsetting spherical bearing to guarantee the accuracy of application of a given compression effort. The loading

Table 1. Steel consumption per $1 \mathrm{~m}^{2}$ of the casing of a steel-concrete load bearing unit.

\begin{tabular}{|c|c|c|c|c|c|c|c|}
\hline \multicolumn{2}{|c|}{ Solid casing } & \multicolumn{4}{|c|}{ Mesh casing (expanded metal mesh) } & \multirow{2}{*}{$\begin{array}{c}\text { Steel saving } \\
\text { coefficient, } \\
\%\end{array}$} & \multirow{2}{*}{$\begin{array}{c}\text { Weight } \\
\text { reduction of } \\
\text { casing, \% }\end{array}$} \\
\hline $\begin{array}{l}\text { Thickness of plate- } \\
\text { workpiece, mm }\end{array}$ & $\begin{array}{l}\text { Weight, } \\
\mathrm{kg} / \mathrm{m}^{2}\end{array}$ & $\begin{array}{c}\text { Plate } \\
\text { designation }\end{array}$ & $\begin{array}{l}\text { Thickness of plate- } \\
\text { workpiece, mm }\end{array}$ & $\begin{array}{c}\text { Overall thickness } \\
\qquad, \mathrm{mm}\end{array}$ & $\begin{array}{l}\text { Weight, } \\
\mathrm{kg} / \mathrm{m}^{2}\end{array}$ & & \\
\hline 4 & 31,40 & PVL 406 & 4 & 12,7 & 15,7 & 52,00 & 34,00 \\
\hline \multirow{3}{*}{5} & \multirow{3}{*}{39,25} & PVL 506 & 5 & 13,0 & 16,4 & 58,22 & 39,58 \\
\hline & & PVL 508 & 5 & 16,8 & 20,9 & 46,75 & 31,79 \\
\hline & & PVL 510 & 5 & 20,5 & 24,7 & 37,07 & 25,20 \\
\hline \multirow{3}{*}{6} & \multirow{3}{*}{47,10} & PVL 606 & 6 & 13,4 & 17,3 & 63,27 & 43,02 \\
\hline & & PVL 608 & 6 & 17,1 & 21,9 & 53,50 & 36,38 \\
\hline & & PVL 610 & 6 & 20,8 & 26,0 & 44,80 & 30,46 \\
\hline
\end{tabular}


of all the samples takes place using two additional elements - steel disks having a thickness of $30 \mathrm{~mm}$ with a diameter equal to the diameter of a concrete core.

During testing measurement of the longitudinal deformations and relative lateral movements (relative to the radius of a certain sample) is made with the help of four clock-type indicators that are fixed on a sample and four digital indicators that are fixed in the middle of the sample height (Fig. 5). The data of a measuring system are read 15 minutes later after having loaded the tested sample with a programmed loading, i. e. after complete stabilisation of the numerical readings of devices. [10].
Loading on all the samples is transferred due to the strict alignment of a structure, a press axis and corresponding additional devices. The tests, which include static axial loadings and low-cycle axial ones, are made until the samples break.

Loading is carried out by means of the phase-by-phase application of load $(F, \mathrm{kN})$ from zero to a set level (including the moment of destruction), and a phase varies within a range of $100-400 \mathrm{kN}$ depending on the type of sample. During low-cycle loading we have full load relief after each phase. The programme of tests predetermines the record of loading cycles.

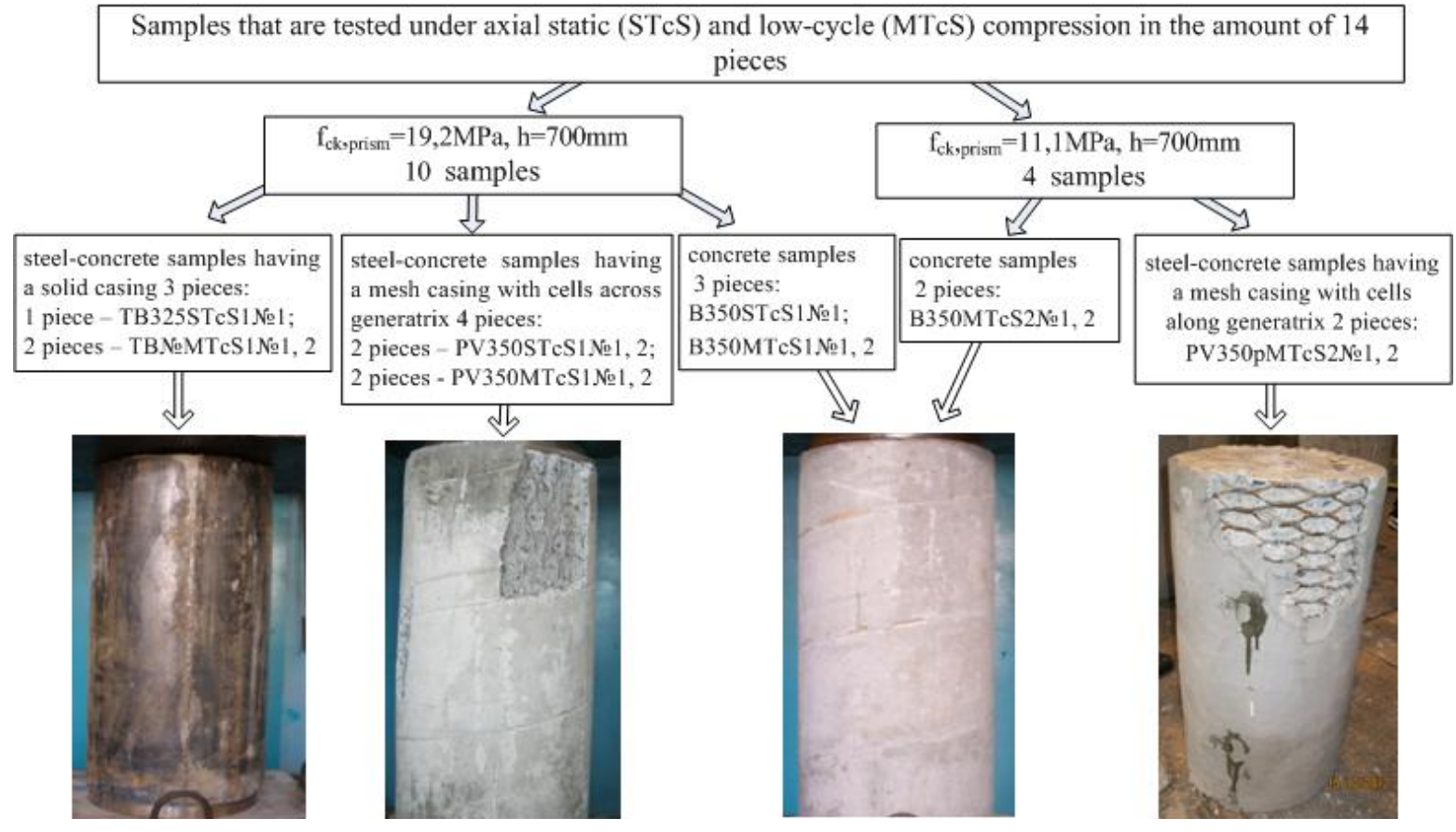

Fig. 3. Structure chart of experimental research of steel-concrete samples of various types and concrete samples without reinforcement under axial static and low-cycle compression.

a)

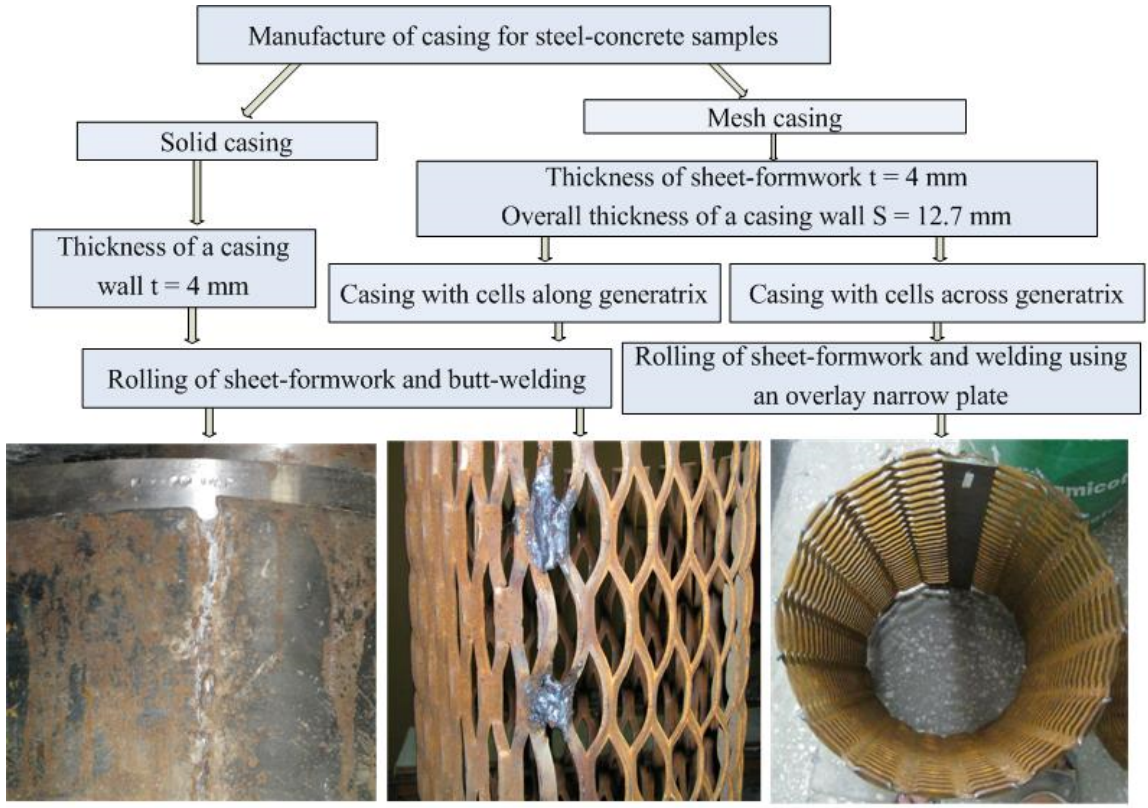

b)
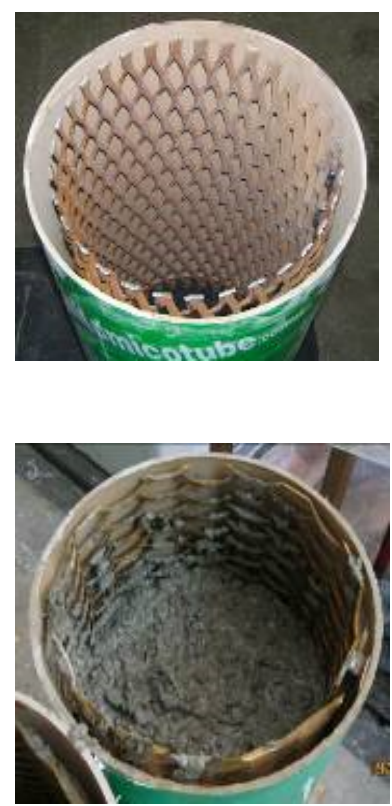

Fig. 4. Features of sample manufacture: a) joining of various steel sheets by welding; b) concreting of samples using a disposable formwork for monolithic construction AMICOTUBE. 


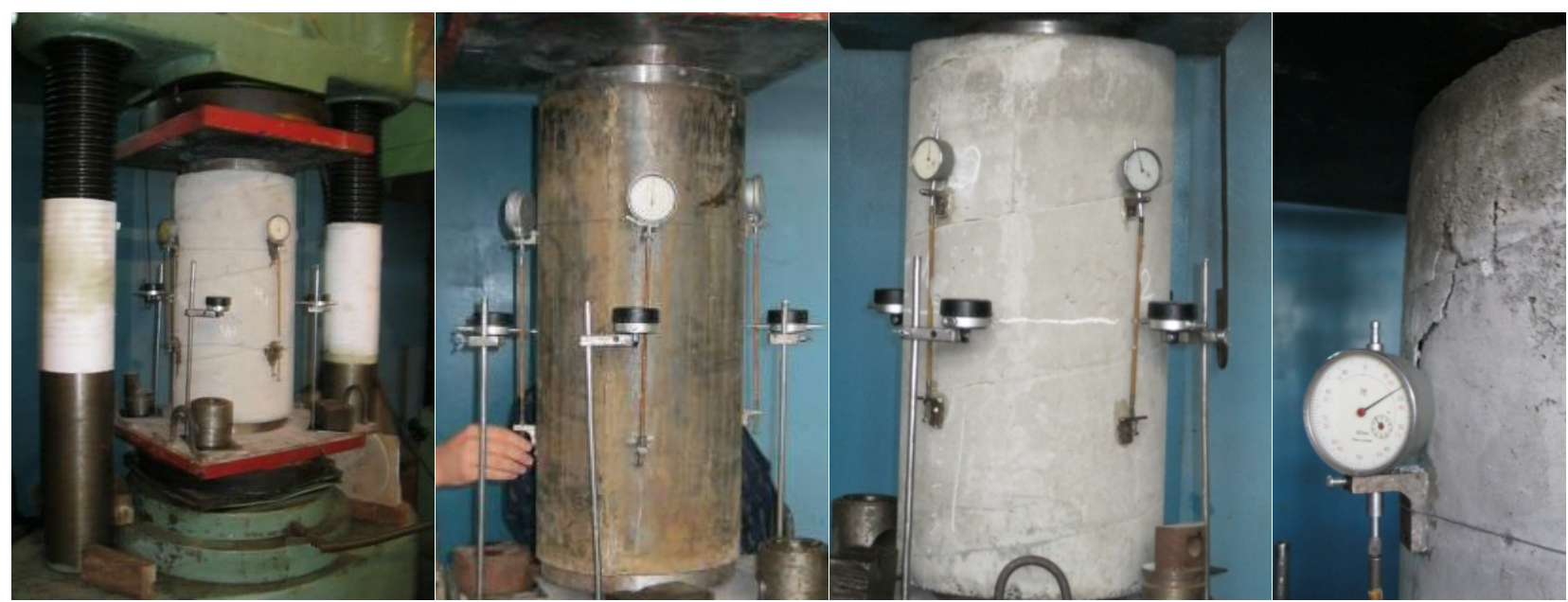

Fig. 5. Installation scheme of a system to measure longitudinal deformations and lateral movements.

\section{Results and discussion}

In the course of experimental research the breaking loads of the samples of all types are recorded, their values are recorded in Table 2. Table 2 also contains the results of the theoretical research of the bearing capacity of the cylindrical steel-concrete units having a solid casing and a mesh casing where cells are located along and across the generatrix of structure, using the methodology that is presented in papers $[9,11]$. Hence, the theoretical calculation of the bearing capacity of a cylindrical bearing structure having a solid casing as well as a mesh casing is performed as follows:

$$
N_{\text {estimated }}=A_{C} f_{c k}+\varphi_{s v} A_{a s, r e d} f_{t k}+\left(\frac{\delta_{a s, r e d}}{R_{m}}+\mu_{s}\right) f_{y k} A_{c},
$$

where $N_{\text {estimated }}$ is the bearing capacity of a cylindrical steel and concrete component; $A_{c}, A_{a s, r e d}$ are the square of the lateral section of a concrete core and the reduced square of a steel casing respectively; $f_{c k}$ is characteristic concrete strength under compression; $f_{t k}, f_{y k}$ are the characteristic steel strength value under tension and the value of steel strength on a fluidity limit correspondingly; $\varphi_{s v}$ is the coefficient that takes into account the decrease of steelconcrete strength due to a welding seam; $\delta_{a s, r e d}$ is the reduced thickness of a steel casing wall; $\mu_{s}$ is the reinforcement coefficient of the lateral section of a cylindrical steel-concrete bearing component $\mu_{s}=A_{a} /\left(A_{a}+A_{a s, r e d}\right) ; R_{m}$ is the mean radius of the steel casing of a cylindrical steel-concrete component.

The bearing capacity increase coefficient is calculated using the ratio between a steel-concrete structure and a corresponding concrete sample without reinforcement.

Table 2. Breaking loads as the results of tests and theoretical calculations.

\begin{tabular}{|c|c|c|c|c|c|c|c|c|c|c|}
\hline 年 & 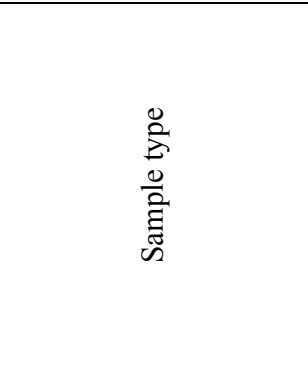 & 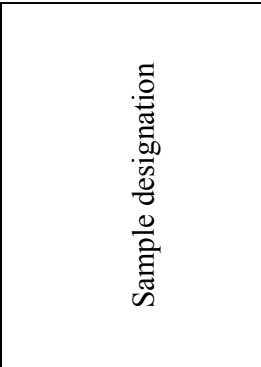 & 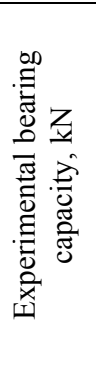 & 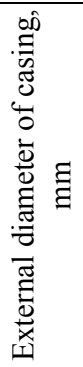 & 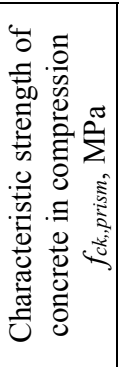 & 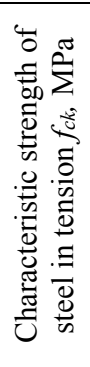 & 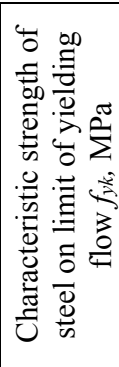 & 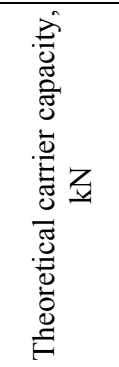 & 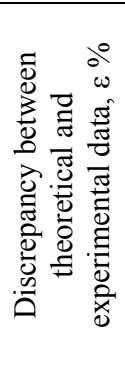 & 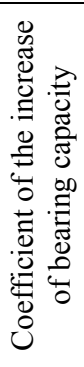 \\
\hline 1 & \multirow{3}{*}{ Solid casing } & TB325CTcS1№1 & 4110 & 325 & 19,2 & 435,6 & 235,15 & 4015,15 & $-2,36$ & 1,67 \\
\hline 2 & & TB325MTcS1№1 & 3960 & 325 & 19,2 & 435,6 & 235,15 & 4015,15 & $+1,39$ & 1,61 \\
\hline 3 & & TB325MTcS1№2 & 4020 & 325 & 19,2 & 435,6 & 235,15 & 4015,15 & $-0,12$ & 1,63 \\
\hline 4 & \multirow{4}{*}{$\begin{array}{l}\text { Mesh casing with cells } \\
\text { along generatrix }\end{array}$} & \begin{tabular}{|l|} 
PV350STcS1№1 \\
\end{tabular} & 1800 & 325 & 19,2 & 365,1 & 222,77 & 1748,46 & $-2,95$ & 1,16 \\
\hline 5 & & PV350STcS1№2 & 1640 & 325 & 19,2 & 365,1 & 222,77 & 1748,46 & $+6,61$ & 1,06 \\
\hline 6 & & PV350MTcS1№1 & 1850 & 325 & 19,2 & 365,1 & 222,77 & 1748,46 & $-5,81$ & 1,20 \\
\hline 7 & & PV350MTcS1№2 & 1750 & 325 & 19,2 & 365,1 & 222,77 & 1748,46 & $-0,09$ & 1,13 \\
\hline 8 & \multirow{3}{*}{ Concrete } & B350STcS1№1 & 2340 & 350 & 19,2 & - & - & - & - & - \\
\hline 9 & & B350MTcS1№1 & 1800 & 350 & 19,2 & - & - & - & - & - \\
\hline 10 & & B350MTcS1№2 & 2350 & 350 & 19,2 & - & - & - & - & - \\
\hline 11 & \multirow{2}{*}{ Concrete } & \begin{tabular}{|l|} 
B350MTcS2№1 \\
\end{tabular} & 1490 & 350 & 11,1 & - & - & - & - & - \\
\hline 12 & & B350MTcS2№2 & 1440 & 350 & 11,1 & - & - & - & - & - \\
\hline 13 & \multirow{2}{*}{$\begin{array}{l}\text { Mesh casing with cells } \\
\text { across generatrix }\end{array}$} & PV350pMTcS2№1 & 2250 & 325 & 11,1 & 365,1 & 222,77 & 2298,36 & $+2,10$ & 1,61 \\
\hline 14 & & PV350pMTcS2№2 & 2360 & 325 & 11,1 & 365,1 & 222,77 & 2298,36 & $-2,68$ & 1,67 \\
\hline
\end{tabular}


The results of the experimental research of the bearing capacity of the tested samples confirm the proposed solution of the steel-concrete load bearing unit having a mesh steel casing where cells are located across a structure generatrix for structure piers in transport infrastructure. Thus, in the samples where the cells are located along generatrix the coefficient of the bearing capacity increase is approximately 1,05 ; it is half of the increase of the bearing capacity in the samples having a mesh casing with cells across the generatrix. In addition, the concentration of the values of the critical efforts of buckling confirms the adequacy of the experimental research. The comparison of the experimental and theoretical bearing capacity values indicates a discrepancy of about $5 \%$. It is worth noting that both the steel-concrete sample in a casing that is made from a solid steel sheet and the sample in a mesh casing with cells across generatrix have approximately equal increase in bearing capacity (by 1,61-1,67 times). At the same time, a mesh casing needs half the iron of a solid casing.

The results of the research are displayed in the diagrams (Fig. 6) where the correlation between the sample longitudinal deformations and the level of lowcycle loading under axial compression are shown.

So, the diagrams of the correlation between the longitudinal deformations and the level of external loading indicate that under low-cycle axial compression both a solid steel casing and a mesh casing with cells along the generatrix decrease the longitudinal deformations of the samples approximately two times as compared to an analogous concrete unit, whereas a mesh casing with cells across generatrix does not influence the value of longitudinal deformations.

In addition, the diagrams of the casing between relative lateral movements and the level of low-cycle loading under axial compression are made for the same samples (Fig. 7).

The diagrams of the casing between the relative lateral movements and the level of low-cycle axial compression indicate that the steel-concrete samples having a mesh casing with cells along the generatrix have movements that are decreased by 1,5 times, and the samples having cells across the generatrix demonstrate movements that are decreased by 4 times as compared with analogous movements of the concrete sample.

\section{Conclusions}

The results, which are obtained in the experimental and theoretical research, enable us to put into practice the proposed structures of cylindrical steel-concrete column piers for engineering constructions in transport infrastructure. The use of the structure, which has cells across the generatrix, enables us to save $52 \%$ of steel as compared with a solid steel casing of analogous thickness. At the same time, bearing capacity increases by 1,6 times as compared with concrete samples without reinforcement.
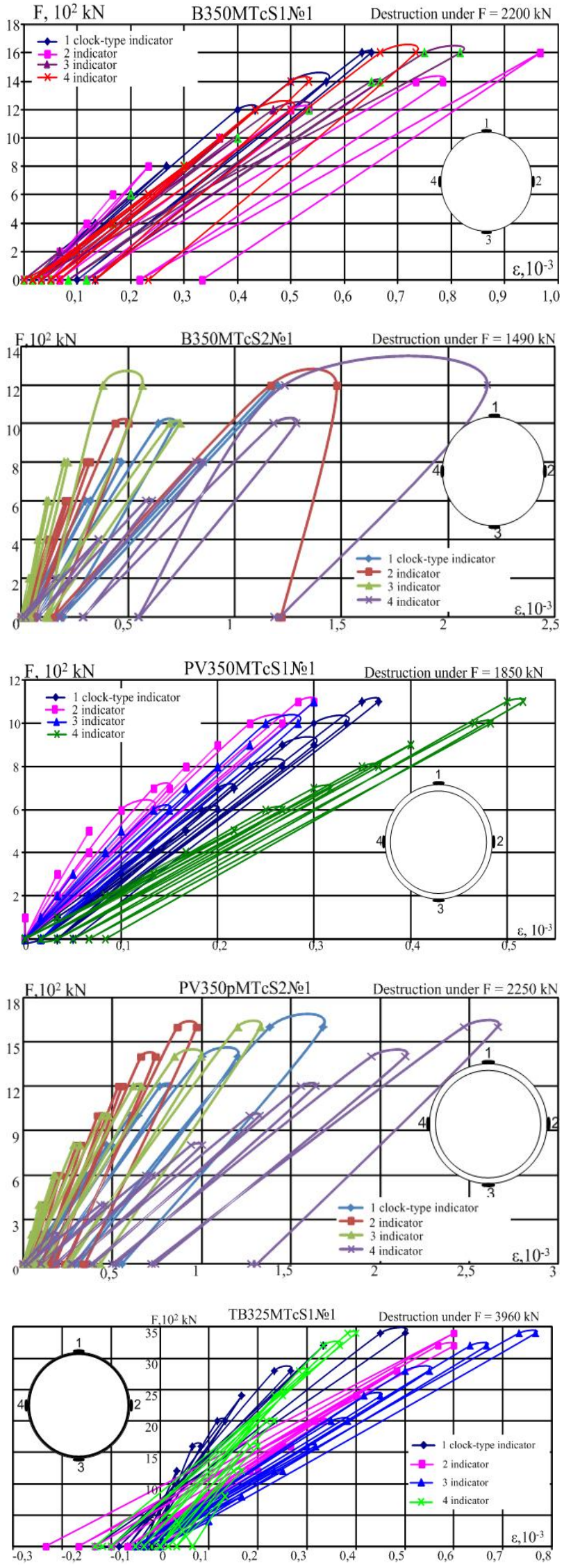

Fig. 6. Correlations between the longitudinal deformations of tested samples and the level of low-cycle axial loading. 

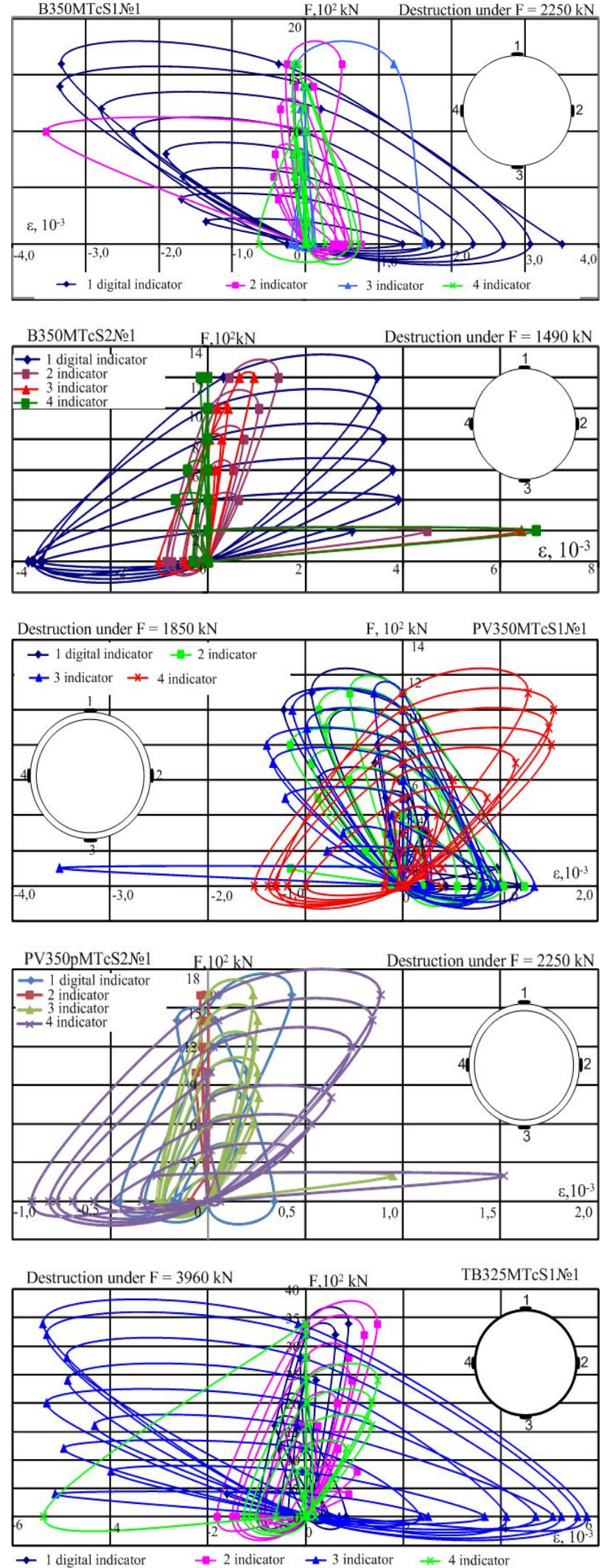

Fig. 7. Correlation between the relative lateral deformations of tested samples and the level of low-cycle axial loading

\section{References}

1. L. Storozhenko, D. Ermolenko, O. Lapenko, Tubeconcrete (in Russian), Poltava, 306 (2010)

2. M. Lachemi, K. Hossain, V. Lambros, Axial load behavior of self-consolidating concrete-filled steel tube columns in construction and service stages, ACI Structural Journal - January-February 2006, 38-47 (2006)

3. E. Chihladze, M. Verevicheva, Operation of cylindrical steel-concrete columns under static shortterm loading (in Russian), Construction, Material Science, Mechanical Engineering, Collection of works of PGASA, 35(4), 47-54 (2005)

4. V. Gnedovskiy, Confinement reinforcement of reinforced concrete structures (in Russian), 126, Leningrad (1981)

5. W. Yi, P. Li, S. Kunnath, Experimental studies on confinement effect of steel hoops in concrete columns, ACI Structural Journal - January-February 2012, 3-10 (2012)

6. V. Shmukler, O. Synkovska, O. Petrova, M. Shutkin, B. Shutkin, Steel-concrete column (in Russian), Useful model patent UA93491E04C3/30, Ukraine (2014)

7. V. Shmukler, Yu. Klimov, N. Burak, Lightened frame systems (in Russian), Kharkov, 336 (2008)

8. Expanded steel mesh. Specification (in Russian), GOST 8706-78, Moscow, 11 s (1978)

9. O. Sinkovskaya, A. Ignatenko, Peculiarities of carrying capacity evaluations of cylindrical CFST columns with new type casing, Transbud-2017, MATEC Web of Conferences, 116, 02031 (2017)

10. O. Synkovska, Rational structures of steel-concrete load-bearing units of bridge footing of new type, Concrete and reinforced concrete - view on the future: III All-Russian conference in concrete and reinforced concrete (in Russian), Moscow, 328-329 (2014)

11. O. Synkovska, E. Surzhan, Cylindrical load-bearing steel-concrete units of building supports and structure footing of new type, their bearing capacity (in Russian), Collection of works of UkrDUZT, 149, 169178 (2014) 